\title{
A Study on Customer Prosumption Concept and Its Impact on Enterprise Value Co-Creation
}

\author{
Jiamian Tian, Lei Shen, Ye Chen \\ Glorious Sun School of Business and Management, Donghua University, Shanghai, China \\ Email:2141460@mail.dhu.edu.cn
}

How to cite this paper: Tian, J.M., Shen, L. and Chen, Y. (2017) A Study on Customer Prosumption Concept and Its Impact on Enterprise Value Co-Creation. Theoretical Economics Letters, 7, 2040-2053. https://doi.org/10.4236/tel.2017.77138

Received: October 21, 2017

Accepted: December 3, 2017

Published: December 7, 2017

Copyright $\odot 2017$ by authors and Scientific Research Publishing Inc. This work is licensed under the Creative Commons Attribution International License (CC BY 4.0).

http://creativecommons.org/licenses/by/4.0/

(c) $\underset{\mathrm{EY}}{\mathrm{C}}$ Open Access

\begin{abstract}
Prosumption, which implies that buyers produce products for their own consumption, is becoming a new phenomenon in the context of network sharing economy. With the development of information technology, customers who are accustomed to online shopping are more and more automatically generating prosumption activities. This paper aims to identify customer prosumption characterized as a kind of compound behavior with integration of information production and consumption in digital age. To do so, a bibliometric analysis identifies the articles that other authors cite the most, their citations, and co-citations, thus enabling the definition of networks of authors and journals from the perspectives of the connotation, behavior, and mechanism. The results suggest that customer prosumption is characterized by "rich" while not "scarce", and enterprises value co-creation is the main form of social activities of customer prosumption. These results also show some gaps in the literature that need further research.
\end{abstract}

\section{Keywords}

Customer Prosumption, Value Co-Creation, Co-Sharing Economy

\section{Introduction}

Nowadays customer prosumption activity characterized by sharing is becoming a new economic form, in line with the penetration of internet to social events. Under the guidance of information and communication technologies, Internet has virtually changed the experience modes of production and consumption, and re-constructed a new social formation [1]. One example is that Linux opens its source code to all programmers for jointly development, modification and usage, which has become the world's second-largest system software after the 
WINDOWS. For another example, there was the rise of shared bicycles (OFO) in 2015. Personal bike sharing for the others can be looked on as "production completed". While, customer's rights to use all the bicycles can be considered as "possession of consumption" [2]. Meanwhile, academic circles are performing research on "prosumption and its social value effect", as Albors-Garrigos et al. [3] note that value can be created by activities between enterprises through a network of value from enterprise level. With value chain theory, specific ways though which information technology creates value for producers and customers should be analyzed further. Esper [4] believes that production and consumption should be integrated together, and the value creation of enterprise supply chain can be implemented through the knowledge management. However, the existing researches only take into account of value creation of prosumption from enterprises perspective while ignore the important role of customers in the process of enterprise value's elevating. For this reason, Meng et al. [5] embed customer into the value creation system of supply chain, under the idea of integrity between production and consumption, and revealed the driving effects and feedback mechanisms of customers in the system. Therefore, we formally define prosumption as "value creation activities undertaken by the consumer that result in the production of products they eventually consume and that become their consumption experience" [6]. However, it is regrettable that, since the customer's prosumption behavior theory does not have a real and substantive progress, as well as the changes in the enterprises structure caused by Internet, the impact mechanism of customer prosumption behavior to enterprise value co-creation has not been revealed at some deep level by the related researches.

From the aspect of application service consumption, mobile channel is considered to be the main sauce of service channel in business field, especially in social network communication. In the first quarter of 2016, active Facebook's daily active users increased $24 \%$ to more than 989 million. It is noteworthy that WeChat has developed rapidly into the world's second largest mobile messaging platform, reaching more than 700 million monthly active users, according to China Academy of Information and Communications Technology (CAICT) ${ }^{1}$. In the context of information consumption in China Internet, customer prosumption phenomenon is becoming popular, such as the importance of Internet has changed from mono-directional way of information downloads to bidirectional way of downloads and uploads, and allow user content sharing and problem solving in Wechat, Weibo, and Zhihu and even other social networks, in this sense, Internet users are both the visits (consumption) and producers of website content (production). However, domestic scholars are rarely involved in the research on the subject, with scattered relevant results, and lack of systematic combing. As for whether prosumption activities can represent the main activities

${ }^{1}$ China Academy of Information and Communications Technology (CAICT) was originally China Academy of Posts and Telecommunications of the former Ministry of Posts and Telecommunications (established in 1957). The study uses the data originally from CAICT. http://www.caict.ac.cn/kxyj/qwfb/bps/201701/t20170110_2186146.htm. 
of customers in the process of enterprise value co-creation in the Internet age, and what are their impacts on the enterprise value co-creation, are worthy further consideration from academic and industry circles. In view of this, this paper combs the domestic and foreign literatures on customer prosumption. Firstly, it re-defines the connotation of customer prosumption, and systematically integrates prosumption activities form and mechanism, discusses the effect results caused by customer consumption activities related with enterprise value co-creation, and how to deal with the changes of enterprise marketing activities caused by the customer prosumption activities, on the basis of the relevant research, the future research directions are prospected, and reveals some enlightenment for the subsequent studies on customer prosumption.

\section{The Rise and Development of Customer Prosumption}

In the Internet society, as the information is becoming a new productivity, and bringing changes in the social organization, which leads to the evolution of the role and behavior of customers. As early as 1984, Toffler [7] put forward the concept of "prosumption", and predicted that human civilization will move forward once again to a personalized civilization in which producers and consumers will integrate again, and the wave of prosumption will sweep the world in twenty-first Century. In the follow-up study, Toffler [8] defines prosumer as a synthetic word of producer and consumer, and points out that prosumers are those for their own use or self-satisfaction, while not those for sale or exchange of creation of goods, services or experience.

In fact, in the network society the customers already have the unprecedented knowledge and skills, and participate in the creation process of products and the knowledge; at the same time, the internal and external organizations of enterprises are also showing a trend of social networking, crowdsourcing to customers those works which before need to spend money to hire staff to complete, and creating products at lower costs by making use of the external network formed by customers prosumption and service dominant logic innovation model [9]. In addition, users upload and provide relevant information exchange by themselves, in websites specialized in image and text sharing, comments and FAQ as Douban, YouTube, dianping.com, Baidu et al., which definitely shows that in the context of network consumption, customer prosumption is becoming a social objective trend.

From the research level of analysis, this paper respectively takes "prosumer, prosuming, prosume, prosumption" as keywords, and retrieves in database as WOS, EBSCO, EMERALD, PQDT, SCIENCE DRIECT ranges from 1996 to 2016, and 269 related articles are found. At the same time, by applying CITESPACE software according to the citation frequency and time dimension, co-citation clustering analysis are portrayed by Figure 1, which is based on the results of the literatures reviews. The relevant researches from Ritzer in 2010 are found at the core position, studies related with prosumption experience three stages evolu- 
Cite Space, v. 5.0.R2 SE (32-bit)

C:IUsers (Administrator (Desktopldata

Timespan: 1996-2016 (Slice Length $=1$ )

Selection Criteria (c, cc, ccv): 5, 4, 10; 3, 3, 20; 3, 3, 20, LRF $=2, \mathrm{LBY}=8, \mathrm{e}=2.0$ Network: $\mathrm{N}=25, \mathrm{E}=19$ (Density $=0.0633$ ) Nodes Labeled: $5.0 \%$
Pruning: MST

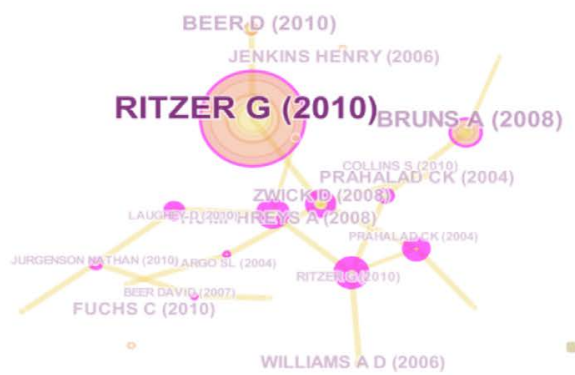

Cite Space, v. 5.0.R2 SE (32-bit) C:IUsersiddministratorlDesktopldata

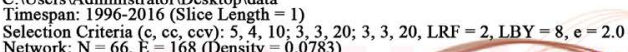
Network: $N=66, E=0$
Nodes Labeled: $5.0 \%$
Pruning: MST

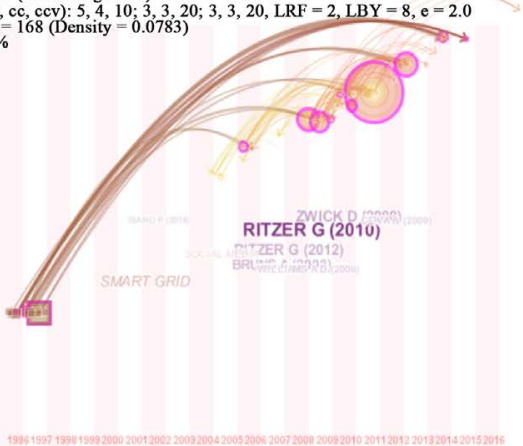

Figure 1. Prosumption document retrieval analysis. (a) Citation frequency analysis; (b) time dimension analysis.

tion in the dimension of time-"value co-creation, system formation, Multi-approaches". Ritzer systematically explains and discusses a series of capital operation and social economic problems related to the prosumption phenomenon, and believes that production and consumption is essentially difficult to be strictly differentiated, for example, the producers' consumption of raw materials for production, while consumers will do production work on the existing goods according to their specific needs (as cooking materials from the market) [10]. Meanwhile, Ritzer also criticizes the dualism ideas of the previous sociologists on production and consumption, and points out that prosumption is the focus that the society should pay attention to.

In the analysis of the time evolution of the prosumption literatures, it can be found clearly. Table 1 illustrates a time zone of the procedure.

1) Value co-creation stage (1996-2004), the stage is mainly focused on the research on prosumption concept and its value, and notices the less attention issue on consumer interaction in the traditional marketing research, and re-constructs the value co-creation topic based on the logic of prosumption.

2) Content enrichment stage (2004-2010), the stage mainly focuses on the status and function of prosumers in the social and economic activities in the Internet context, and notes that with the interests to WEB2.0 technology, the content and form of prosumers and prosumption activities are further enriched.

3) Multi-approaches stage (since 2011), this stage mainly focuses on the study on prosumer and enterprise value, prosumer and prosumption society, and takes into account the revolutionary impact brought by prosumption forms represented by co-sharing economy to the traditional marketing theory, hence, prosumption fields expand and extend from the individual observation and micro level to the enterprise level, and even the macro society level.

In general, the customer prosumption study has entered the stage of value co-creation and ecology co-creation, researchers pay attention to the mode of value creation and transmission in the network of enterprise value co-creation, and focus on tracking the multi-dimensional value co-creation process of relationship network constructed by the interaction of the external environment 
Table 1. Literature review on customer presumption.

\begin{tabular}{|c|c|c|}
\hline Evolution stages & Stage characteristics & Main representative documents \\
\hline \multirow{6}{*}{$\begin{array}{l}\text { Value co-creation stage: } \\
\text { the rise of research on } \\
\text { prosumption value }\end{array}$} & Customer value co-creation: Non-internet enterprises are using the & Prahalad (2004), \\
\hline & "prosumer" concept, to subvert the traditional concept that value is created & Vargo (2004), \\
\hline & by the enterprise independently, emphasize the innovation from its & Chu (2011), \\
\hline & business model and organization model. These enterprises subcontract & Yi (2013), \\
\hline & certain tasks of the value chain to the customers to undertake & Cao (2013), \\
\hline & corresponding value creation activities & Zhang (2013) \\
\hline
\end{tabular}

Prosumption value co-creation: Customers are incorporated into the main and its subsequent progress body of value co-creation, the main ways of value co-creation as co-creations

Content rich stage: analysis of prosumer behavior based on Internet new media practice
Multi-approaches: analysis of prosumer behavior based on Internet new media practice between enterprises, co-creations between enterprise and customer, co-creations between customers, emphasize whether the prosumption behaviors between customers could affect each other, and finally focus on customers' acquisition of better consumption value experience.

The rise of the concept of prosumption: Prosumption is a compound word of producer and consumer, which was put forward by Toffler in 1984 . Ritzer put forward the integration model of production and consumption, Shen put forward that productive consumption of information is the

Yadav \& Pavlou (2014), Shen (2016)

Toffler (1984), Ritzer (2010), Shen (2013)

Godes (2004), Williams (2006), Liu (2006), Bruns (2008), Ritzer (2009), Rieder (2010), Beer (2010), Woermann (2012), Boffo (2014)

Zwick (2008),

Artificial Intelligence: With the progress of technology, the prosumers are not only natural persons, the emergence of intelligent prosumption machines are once again triggering a research boom

Business Model: Describes the delivering mode of Internet enterprise value. Consumer research has entered the business model and practice related to Internet companies

Prosumption Society: The research field extends from the micro level to the macro social level, focusing on the research of the prosumer and the prosumption society

Sharing Economy: The prosumption behavior is the root cause of the economic and social subver sion, and the prosumer is closely related to the rise of the sharing economy

Internet of Things: The research of prosumption extends to the field of automation and self-organization of intelligent devices, and discusses the construction of the Internet of things which are interrelated and run together

Brand Value: the research field extends from the micro level to the middle enterprise level, focusing on the customer prosumer and enterprise value.
Recuber (2012),

Siuda(2012),

Osenthal (2014)

Trusov (2009),

Henry (2010),

Li (2016)

Ritzer (2010),

Ritzer (2013)

Botsman (2010), Belk (2014),

Schor (2014), Wu (2015)

Magi (2012), Souza (2016), Xinaris (2016), Kirsi (2016)

Pavlou (2013), Cova (2015), Rayna (2015), Benitez (2016), He (2016), Shen (2016)

between enterprise brand and customer prosumption, enterprise employees and customers, as well as between other stakeholders outside customer prosumption.

\section{Researches on Customer Prosumption Behavior Pattern}

Toffler [11] first put forward the concept of production and consumption united 
as one, and defines prosumption activities are those activities of customers for their own use or self-satisfaction, while not those for sale or exchange of creation of goods, services or experience. Ritzer [12] argues that the industrial revolution has separated production and consumption to some extent, but he also believes that even in the industrial revolution, production and consumption are not completely separated (such as raw materials consumed by the producers to cook for sell or use by themselves; or used by consumers for cooking and eating by themselves). At the same time, Ritzer [13] proposed a continuum model of prosumption, and re-defined production and consumption as prosumption-as-production and prosumption-as-consumption, and he argues that prosumption is such a process widely presented as a continuum rather than a single process (or phenomenon).

Figure 2 shows that two poles of prosumption continuum model were been redefined as prosumption-as-production ( $\mathrm{p}-\mathrm{a}-\mathrm{p}$ ) and prosumption-as-consumption ( $\mathrm{p}-\mathrm{a}-\mathrm{c})$. This illustrates that production and consumption exist as blend poles, there is no pure forms and balanced in the middle of " $p-a-p$ " and " $p-a-c$ ". In a sense, Ritzer extracts the two primary conceptual prosumption dimensions of production and consumption, sub-types of prosumption. "p-a-p" results in better outcomes as compared to what would be achieved alone by producer (firm) independently. IKEA, DIYs are means of "p-a-p" which lead prosumers to produce their own bookcases at home. "p-a-p" consists of direct or indirect "co-working with customers". While "p-a-c" arises through a process of consumption, which may be mostly independent of the company's intervention or exchange. MOOCs ("p-a-c") lead students to consume college-level courses at home, providing users information resource integration services across the time and the space. ATMs lead to both taking out money from their bank account and cash recycling ("balanced prosumption"). That is to say, It is prosumption that is the more general process that subsumes the other two.

Researches on prosumption behavior has become increasingly crucial during the past decade. Shen [14] has pioneered the use of the consumer role model to classify network information consumption behaviors, and divide virtual community customers into 9 types according to contribution and association degree, which embodies the idea of unity of production (information content generation) and consumption (information content browsing). In the follow-up study, Shen [15] from the perspective of consumer behavior in the field of information, argues that the Internet information consumption is the basis for the prosumption economic behavior, the information consumption of production is the key to the Internet information prosumer activities. Meng [5] analyzes prosumption behavior patterns from two kinds of model, that is user to generate content and

\begin{tabular}{|c|c|c|}
\hline Prosumption-as-Production & "Balanced" Prosumption & Prosumption-as-Consumption \\
\hline
\end{tabular}

Figure 2. Prosumption continuum model. 
customer to bear the value chain, and argues that the former mainly exists in the digital product knowledge, while the later exists in the general industrial product service.

Generally, the current researches on customer prosumption behavior has not yet formed a system in China, mostly exist in forms of description of the case or a business story, related researches are still in scattered and isolated states.

In addition, concerning Meng's viewpoint of the two categories of consumer behavior, "user generated content" agrees with the study of Shen et al. on network information consumption, while the study on 'value chain born by the customer' triggers another idea. As the study of customer citizenship behavior also involves value production from customer to the enterprise, so we need to distinguish the difference between customer citizenship behavior and customer prosumption. In 1990s, the theory of organizational citizenship behavior began to attract the attention of marketing scholars. Gruen [16] argues that customers also has similar citizenship behavior as organizing employees, hence, he defines the citizenship behavior as a kind of constructive behavior which is for customer, appreciated by the organization or perceived value, while not directly related to the role of the customer but helpful to the organization. Bettencourt [17] tries to use the concept of customer voluntary behavior as a substitute for citizenship behavior, and considers that customer voluntary behavior is a customer behavior which is customer self-determination and helps organization to improve the quality of service. Bove [18], however, believes that some voluntary behaviors of the customer may lead to conflicts with the organization's goals, so they believe that the benefits of the organization is the key difference between customer organizational citizenship behavior and other customer voluntary behavior. At present, the widely used domestic concept of customer citizenship behavior is clearly put forward by Groth [19], who believes that customer citizenship behavior is not the necessary activity for successful delivery of the production or service, action, not to mention customer voluntary, this kind of behavior in general is beneficial to the improvement of enterprise service quality and efficiency.

Hence, from the behavioral motivation perspective, what the customer citizenship behavior emphasizing is the customer to recognize their individual behavior is "useful" to the organization, while, the customer prosumption behavior itself is something "useful" to an organization, which does not need the customer to recognize that their individual behavior is "useful" to the organization, it is the characteristic of Internet information consumption makes the prosumption behavior to benefit the "organization" automatically. From the behavioral subject perspective, customer citizenship behavior only emphasizes the benefits brought by customer self-determination behavior to organization, from the angle of the customer. While prosumption behavior studies the behavioral subject which unite production and consumption as one, and thus naturally including the producer and the consumer of the two behavioral subjects. From the behavioral process perspective, the customer citizenship behavior emphasizes too much on the customer's unilateral activity, while the prosumption behavior fo- 
cus on the interaction between the enterprise and the customer in the two aspects of production and consumption. From the behavioral result perspective, the customer citizenship behavior underlines benefits to the organization, while the prosumption behavior underlines the value co-creation and sharing. Obviously, customer pronsumption behavior is a proposition deserves more extensive research than the customer citizenship behavior in concept and connotation, but there is an overlap between the two in terms of "benefits to the organization", as the related research results of customer citizenship behavior can provide some theoretical support for the research of prosumer behavior.

\section{Study on Customer Prosumption's Impact on Enterprise Value Co-Creation}

In recent years, the theory of value co-creation has been developed rapidly in the domestic and foreign scholars, and gets gradual improvement [20]. In the field of production, the core value of value co-creation emphasizes the key role of customer knowledge contribution or creative activities in the development of new products. While in the field of consumption, the customer has been emphasized as "co-production" role in the R \& D process of enterprise, which especially in the service industry is regarded as a part-time staff, in a service dominant logic perspective this analysis framework covers value co-creation of interactions of three parties-the enterprise, the customers and other stakeholders [21] [22]. In the follow-up study, Zhang and Deng [23] analyze the problem of enterprise value co-creation from four different levels: enterprise-employee, enterprise-customer, employee-customer, enterprise-the other different stakeholders, and makes the corresponding empirical test. Through the analysis of customer prosumption behavior, we can say that the prosumer behavior is similar as the customer citizenship behavior in beneficial aspect to organization, therefore, from the perspective of the value chain, it can be concluded that customer prosumption has a certain impact on the enterprise value co-creation, and which should also be analyzed from four different aspects: enterprise-employee, enterprise-customer, employee-customer, enterprise-the other different stakeholders.

Unfortunately, the existing research does not relate to customer pronsumption behavior measurement, however, it can be seen from the previous studies that customers have an impact on enterprise value co-creation through two activity dimensions of participation and citizenship [24] [25].

At the same time, in the context of network information consumption, there are two kinds of value production process: "automatic" and "initiative" in the behavioral motivation of prosumption, therefore, under the framework of enterprise value co-creation, this study suggests that customer's prosumer behavior can be measured from two aspects: participation behavior (automatic prosumption) and citizenship behavior (initiative prosumption). The research on participation behavior, such as Chu and Kim [26] think that customer participation behavior includes dimensions as information sharing, responsibility behavior 
and interpersonal interaction; Cao et al. [27] point out that customer participation behavior includes investment, cooperative production, information sharing, providing advice, interpersonal interaction and loyalty behavior. Research on citizen behavior, Gruzd et al. [28] point out that customer citizenship behavior includes four acts: recommendation, feedback, help and tolerance of the four acts. Zhang and Dong [29] divide the virtual brand community customer citizenship behaviors into two categories: CCBO (refers to organizational citizenship behavior: support, feedback, tolerance and supervision) and CCBI (refers to the individual citizenship behavior: help-Seeking, response, sharing and support) two categories

To sum up, this study suggests that prosumer behavior should be measured from participation and citizenship two dimensions. Among them, the dimension of participation involves investment, cooperation, interaction, loyalty and the other indicators, the dimension of citizenship involves advocacy, feedback, tolerance and supervision, as well as help, response, sharing and support. At the same time, according to the research results of Zhang et al., this study also forms a conceptual model of the impact of customer consumption on the enterprise value co-creation (see Figure 3 ). This model emphasizes the concrete mechanism of customer prosumption to enterprise value co-creation

1) From the perspective of behavioral motivation, customer consumption behavior is mainly composed of two dimensions of participation and citizenship, in which the dimension of participation represents process of automatic prosumption of value co-creation, while the dimension of citizenship represents process of initiative prosumption of value co-creation.

2) Enterprise value co-creation includes 4 aspects: enterprise-employee, enterprise-customer, employee-customer, enterprise-the other different stakeholders, among which, the aspect of "enterprise-employee" is in the core position of value co-creation, which can be considered as the organizer of the value co-creation process, and has an impact on the other three value co-creation aspects.

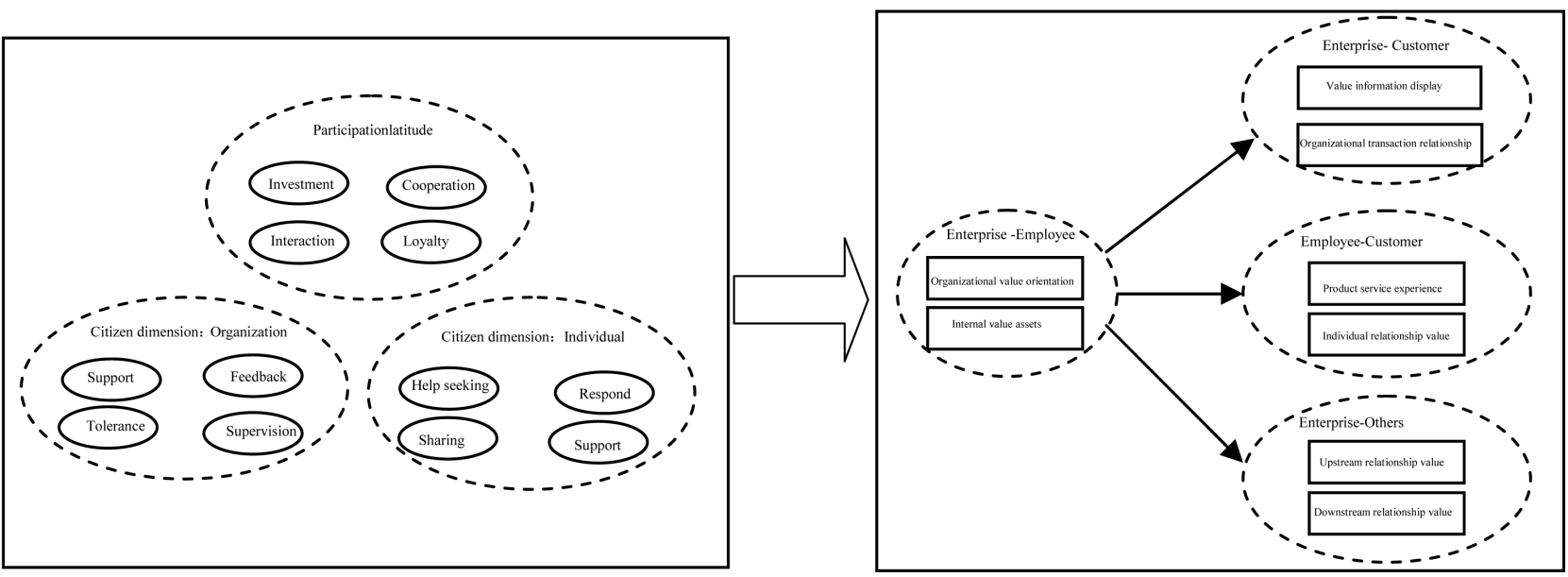

Figure 3. Conceptual model of customer prosumption's impact on value co-creation. 
3) The customer prosumption behavior has an impact on the enterprise value co-creation process, but the co-creation expanding completely around the core aspect of "enterprise-employee", that is to say, the realization of customer prosumption value is based on the value added results of the enterprise.

\section{Discussion}

Sharing economy is a new economic model, the prosumption behavior based on the Internet and Web 2.0 is a revolutionary subversion. Although some welfare effects of the sharing economy are uncertain, but the core value of using of Internet information technology to improve the efficiency of resource use and allocation has been widely recognized [30]. As a result, for those Internet companies with a large number of multi-dimensional interaction and relationship marketing, prosumer behavior has become a new starting point for understanding the value co-creation of the enterprise. Below are conclusions of this paper obtained through the relevant research:

1) The key body of Internet sharing economy is the customer prosumption. While the characteristics of customer prosumption is "rich" rather than "scarce", and what the enterprise focus is on "quality" rather than "efficiency". Because everyone is endowed with a tool to generate content, thus in the Internet sharing economic activities, the daily personal instant original or shared messages generated in the WeChat platform and the daily massive new content produced in Sina micro-blog can even affect social public opinion direction, while the corresponding content in websites as Guokr almost been provided by the network user's interaction. The richness of information production can be satisfied by a large number of customer prosumption activities, which also provides the basis for enterprise value co-creation.

2) Information consumption is the social basis of customer prosumption. In the Internet context, the cost of information acquisition becomes extremely low, and the interaction activity of information exchange becomes more and more convenient. The narrow sense of information consumption only refers to the information of goods or services to buy and use, but at the premise of extensive use of Internet technology, information consumption refers to a continuation of the process of social information production and communication, and contains information demand, Information possession, information processing and information regeneration, as well as the attributes of decision purpose and decision value of information consumption.

3) The consumer's cognitive structure will change accordingly. It will be stored in the long-term memory, which would be possibly further transformed into new knowledge under certain conditions. While, from the viewpoint of prosumer, network consumption behavior has the characteristics of both information consumption and production. Productive information consumption is the basis of Internet information production and consumption activities. Hence, the information consumption activities in this series of activities can be regarded as a kind of productive information consumption, and the consumption of in- 
formation is the social basis of the formation of prosumers.

4) Value creation is the main form of customer prosumption, although the study only focus on the controversy of the basic concept of prosumption, there is no in-depth discussion on how prosumption activities create value, but some user generated content (UGC) studies have shown that the information prosumption activities are creating value for enterprises and customers. While the wide application of big data technology will allow enterprises to design a better product search ranking system, through the statistical analysis of customer information browsing, so as to better meet the corresponding customer preferences for product features. For example, it is proved from the side of the Wei incident that the product recommendation represented by conventional data measurement means as valence and quantity has been unable to meet the needs of customers in the Internet Age. Customers are more concerned about product experience review generated by other users based on their individual experience from real consumption, which been co-created as a powerful market tool through thousands of iteration of information consumption, so as to help the enterprise to "listen" to the customer's views on the products of enterprise and its competitors, and finally transform to the visual market structure and competitive landscape.

\section{Limitations and Future Lines of Research}

In addition, it should be pointed out that these new research ideas still remain in the discussion level of concept description, case study of the consumption product, and the general brand management, while, a clear theoretical framework, operable key constructs, and empirical research conclusions with certainty are still missing [31] [32]. Especially with the rise of the value co-creation study, it needs more study to the value co-creation process through interaction activities of the customers, enterprises and other stakeholders, and the analysis to the way of value performance improvement of Internet companies has not yet been combined with behavioral characteristics of the production and consumption united as one in the network information consumption context [33].

Therefore, in the follow-up study, this paper believes that the internal mechanism of Internet companies' value co-creation should be discussed from the perspective of service oriented logic: Is prosumption activity the characterization of the main track of customers in the process of Internet enterprise value cultivation? What are the main dimensions of Internet enterprise value co-creation activities? Is there any impact on the main dimensions of customer presumption? How the enterprise value c-creation activities combine to affect the customer's corresponding cognition? At the same time, it is hoped that through relevant research, it can provide effective help for Internet companies to obtain positive customer value cognition.

\section{Conclusion}

In conclusion, the Internet prosumer behavior is far more than the behavior of 
information prosumption, but with more abundant performance. Prosumers are worthy of the attention of scholars in the performance of arts, creation, games, food and beverage, and even energy production. In addition, prosuming economy makes capital operation boundaries become blurred, it is possible to make the capital economic operation into a real value sharing stage, but how to share the value of co-creative activities to prosumers will bring a significant economic and social problem. Thanks to the bright future where the Internet and networking technology gradually be mature, there are more topics about economic activity phenomenon of customer prosumption worthy of in-depth discussion, which will actively promote the society to a more efficient and green direction.

\section{Funding}

The paper is supported by National Social Science Foundation of China (11BGL067), Fundamental Research Funds for the Central Universities (17D310807).

\section{References}

[1] Castells, M. (1996) Rise of the Network Society: The Information Age: Economy, Society and Culture. Blackwell Publishers, Inc., 113-129. http://www.langtoninfo.com/showitem.aspx?isbn=0631221409

[2] Huemer, L. (2006) Supply Management: Value Creation, Coordination and Positioning in Supply Relationships. Long Range Planning, 39, 133-153.

http://tsuhhelweb.tsu.edu:2052/science/article/pii/S002463010600015X https://doi.org/10.1016/j.lrp.2006.04.005

[3] Albors-Garrigos, J., Hervas-Oliver, J.L. and Marquez, P. (2009) Internet and Mature Industries: Its Role in the Creation of Value in the Supply Chain. The Case of Tile Ceramic Manufacturers and Distributors in Spain. International Journal of Information Management, 29, 476-482.

http://tsuhhelweb.tsu.edu:2052/science/article/pii/S0268401209000322 https://doi.org/10.1016/j.ijinfomgt.2009.03.005

[4] Esper, T.L., Ellinger, A.E., Stank, T.P., et al. (2010) Demand and Supply Integration: A Conceptual Framework of Value Creation through Knowledge Management. Journal of the Academy of Marketing Science, 38, 5-18. https://link.springer.com/article/10.1007/s11747-009-0135-3 https://doi.org/10.1007/s11747-009-0135-3

[5] Meng, Q., Dong, J. and Li, C. (2012) Study on Supply Chain Value Maximization Based on New Prosumer. Chinese Journal of Management Science, 20, 102-109. http://www.cnki.com.cn/Article/CJFDTOTAL-ZGGK201206013.htm

[6] Xie, C., Bagozzi, R.P. and Troye, S.V. (2008) Trying to Prosume: Toward a Theory of Consumers as Co-Creators of Value. Journal of the Academy of Marketing Science, 36, 109-122. https://link.springer.com/article/10.1007/s11747-007-0060-2 https://doi.org/10.1007/s11747-007-0060-2

[7] Toffler, A. (1980) The Third Wave: The Corporate Identity Crisis. Management Review, 8-14.

http://lib.just.edu.jo:3627/eds/detail/detail?vid=2\&sid=4e999ea8-b01b-404c-a453-e8 a36f128eb6\%40sessionmgr4007\&bdata=JnNpdGU9ZWRzLWxpdmU\%3d\#db=edb $\underline{\mathrm{AN}}=6267645$ 
[8] Toffler, A. (2013) Revolutionary Wealth. New Perspectives Quarterly, 30, 122-130. http://onlinelibrary.wiley.com.ezproxy.lib.ctcn.edu.tw:2048/doi/10.1111/j.1540-5842 2006.00818.x/full https://doi.org/10.1111/npqu.11414

[9] Meng, T. (2012) The Emergence of "Prosumers" and Management Innovation in the Network Society. Comparative Economic and Social Systems, 161, 205-211. http://www.cnki.com.cn/Article/CJFDTOTAL-JJSH201203020.htm

[10] Ritzer, G. and Jurgenson, N. (2010) Production, Consumption, Prosumption the Nature of Capitalism in the Age of the Digital "Prosumer". Journal of Consumer Culture, 10, 13-36. http://journals.sagepub.com/doi/pdf/10.1177/1469540509354673 https://doi.org/10.1177/1469540509354673

[11] Toffler, A. (1981) The Third Wave. Bantam Books, New York, 1-12.

[12] Ritzer, G. (1999) Enchanting a Disenchanted World: Revolutionizing the Means of Consumption. Pine Forge Press, Thousand Oaks, 111-123.

[13] Ritzer G. (2013) Prosumption: Evolution, Revolution, or Eternal Return of the Same. Journal of Consumer Culture, 1, 1-22. http://onlinelibrary.wiley.com/doi/10.1111/socf.12142/full

[14] Shen, L. and Li, Y. (2009) The Study about On-Line Information Interaction in Virtual Community Affecting Internet User's Consumption Role Changing. The 4 th International Conference on Management and Service Science, 9, 91-94. http://ieeexplore.ieee.org/document/5301137/

[15] Shen, L. (2013) Consumer Behavior: Theory and Practice. Renmin University of China Press, 67-89.

[16] Gruen, T.W. (1995) The Outcome Set of Relationship Marketing in Consumer Markets. International Business Review, 4, 447-469.

http://tsuhhelweb.tsu.edu:2052/science/article/pii/0969593195000267 https://doi.org/10.1016/0969-5931(95)00026-7

[17] Bettencourt, L.A. (1997) Customer Voluntary Performance: Customer as Partners in Service Delivery. Journal of Retailing, 73, 383-406. http://www.sciencedirect.com/science/article/pii/S0022435997900245 https://doi.org/10.1016/S0022-4359(97)90024-5

[18] Bove, L.L., Pervan, S.J., Beatty, S.E., et al. (2009) Service Worker Role in Encouraging Customer Organizational Citizenship Behaviors. Journal of Business Research, 62, 698-705. http://tsuhhelweb.tsu.edu:2052/science/article/pii/S014829630800177X

[19] Groth, M. (2005) Customers as Good Soldiers: Examining Citizenship Behaviors in Internet Service Deliveries. Journal of Management, 31, 7-27. http://journals.sagepub.com/doi/abs/10.1177/0149206304271375 https://doi.org/10.1177/0149206304271375

[20] Zhou, Z., Zhang, J. and Xiong, Y. (2014) How Do Introversion-Extraversion Personality Traits Influence Knowledge Sharing Behavior in Online Brand Communities: The Mediation of Network Centrality and Reciprocity Norm. Nankai Business Review, 17, 19-29. http://www.cnki.com.cn/Article/CJFDTOTAL-LKGP201403003.htm

[21] Gronroos, C. and Voima, F.P. (2013) Critical Service Logic: Making Sense of Value Creation and Co-Creation. Journal of the Academy of Marketing Science, 41, 133-150. https://link.springer.com/article/10.1007/s11747-012-0308-3 https://doi.org/10.1007/s11747-012-0308-3

[22] Wei, H., Yao, Z. and Liang, Y. (2010) Research on Service Brand Asset Based on the 
Enterprise-Customers-Stakeholders Trichotomy Interaction: An Analytical Framework. Journal of Jinan University (Philosophy and Social Sciences Edition), 1, 79-84. http://www.cnki.com.cn/Article/CJFDTOTAL-JNXB201001014.htm

[23] Zhang, J. and Deng, H. (2013) Key Dimensions of Brand Value Co-Creation and Its Impacts upon Customer Perception and Brand Performance: An Empirical Research in the Context of Industrial Services. Nankai Business Review, 16, 104-115. http://www.cnki.com.cn/Article/CJFDTOTAL-LKGP201302012.htm

[24] Lu, J. and Wang, Y. (2011) Relationship between Customer Involvement in Service Innovation and Innovation Performance: Literature Review and Model Development from Perspective of Customer Knowledge Transfer. Chinese Journal of Management, 8, 1566-1574.

http://www.cnki.com.cn/Article/CJFDTOTAL-GLXB201110025.htm

[25] Tu, J. and Zhang, M. (2013) Empirical Study of the Effect of Interaction on Co-Created Value in Virtual Community. Journal of Hunan University (Natural Sciences), 11, 114-119.

http://www.cnki.com.cn/Article/CJFDTOTAL-HNDX201311019.htm

[26] Chu, S. and Kim, Y. (2011) Determinants of Consumer Engagement in Electronic Word of Mouth (eWOM) in Social Networking Sites. International Journal of Advertising, 30, 47-75. https://search.proquest.com/docview/305004132 https://doi.org/10.2501/IJA-30-1-047-075

[27] Cao, H., Zheng, Q. and Wei, F. (2013) Classification of Customer Participation Behavior Based on Multi Perspective. Journal of Modern Management Science, 3, 41-44. http://www.cnki.com.cn/Article/CJFDTOTAL-XDGL201303015.htm

[28] Gruzd, A., Wellman, B. and Takhteyev, Y. (2011) Imagining Twitter as an Imagined Community. American Behavioral Scientist, 55, 12-94.

http://journals.sagepub.com/doi/full/10.1177/0002764211409378 https://doi.org/10.1177/0002764211409378

[29] Zhang, Y., Dong, D. and Liu, S. (2013) The Concept and Scale Development of Customer Citizenship in Virtual Community. Journal of Dalian University of Technology (Social Science Edition), 34, 30-35. http://www.cnki.com.cn/Article/CJFDTOTAL-DLGD201303005.htm

[30] Wu, X. and Shen, J. (2015) The Connotation of Sharing Economy and Its Extension. Reform Journal, 262, 52-60. http://www.cnki.com.cn/Article/CJFDTOTAL-REFO201512007.htm

[31] Jensen, M.B. and Klastrup, K. (2008) Towards a B2B Customer-Based Brand Equity Model. Journal of Targeting, Measurement and Analysis for Marketing, 16, 122-128. https://link.springer.com/article/10.1057/jt.2008.4 https://doi.org/10.1057/jt.2008.4

[32] Shen, L. and Zheng, Z. (2014) A Review of Context of Online Consumer Behavior and the Construction of Double-Track Online Consumer Decision-Making Model. Foreign Economics and Management, 8, 53-61. http://www.cnki.com.cn/Article/CJFDTOTAL-WGJG201408006.htm

[33] Shen, L. and Wei, X. (2016) The Production and Consumption Activities in the Sharing Economy: A Review and Direction. Journal of Creative Economy and Management, 1, 18-25. 